\title{
Assessment of Community Based Climate Change Risk Focusing Agriculture and Fisheries Sector in Haor Areas of Bangladesh
}

\author{
Ahmmed Zulfiqar Rahaman1, Gopal Chandra Sarker², Bhuiya Md. Tamim Al Hossain1, \\ Sadequr Rahman Bhuiyan², A. S. M. Julker Naem \\ ${ }^{1}$ Center for Environmental and Geographic Information Services (CEGIS), Dhaka, Bangladesh \\ ${ }^{2}$ Haor Infrastructure and Livelihood Improvement Project (HILIP), Local Government Engineering Department (LGED), Dhaka, \\ Bangladesh \\ Email: azr.wre@gmail.com, gopalpdhilip@gmail.com,cetamim@gmail.com,ceesadeq@gmail.com, julkerzimi@gmail.com
}

How to cite this paper: Rahaman, A.Z., Sarker, G.C., Al Hossain, B.Md.T., Bhuiyan, S.R. and Julker Naem, A.S.M. (2021) Assessment of Community Based Climate Change Risk Focusing Agriculture and Fisheries Sector in Haor Areas of Bangladesh. Atmospheric and Climate Sciences, 11, 342-362.

https://doi.org/10.4236/acs.2021.112020

Received: March 8, 2021

Accepted: April 27, 2021

Published: April 30, 2021

Copyright $\odot 2021$ by author(s) and Scientific Research Publishing Inc. This work is licensed under the Creative Commons Attribution International License (CC BY 4.0).

http://creativecommons.org/licenses/by/4.0/

\begin{abstract}
The research paper aims at understanding the level of climate change risk of the Haor areas of Bangladesh. It follows a participatory approach, using Focus Group Discussion (FGD) and Key Informant Interview (KII) to identify important climate change induced hazards, assess the probability of occurrences of the hazards and level of their consequences. Using geo-spatial techniques, the paper prepares hazard risk maps and risk hotspot maps. Policy documents, previous researches, and Government statistics and reports helped to develop the concepts and planning of the research. The unparalleled hydro-ecological attributes of Haor areas pose both opportunities and constraints for the local population. Poverty, lack of basic infrastructure and amenities, awareness and external support have already put the people in Haor areas in a vulnerable situation while the recurring natural hazards and shifting pattern of climate are making the constraints nearly unmanageable. Excessive rainfall in the monsoon and drought in the dry season is affecting the farming and fishery-based communities the most. The community perceptions on hazards, their occurrences, consequences and relative importance of each hazard for the agriculture or fisheries sector in the study area have been collected from the FGDs and subsequently analyzed to produce individual and multi-hazard risk maps for the area based on scoring. This information is also used to rank the Upazillas in the study area depending on risk level. The community people were also asked to select the important elements or structural facilities at risk in their area needed for their life and livelihood.
\end{abstract}


Based on this selection, risk hotspot map for the study area has been prepared using GIS based weighted overlay methods. The final risk hotspot map identifies about hundred unions in the area as hotspots. This paper might encourage the local government organizations to make choice on the intervention as well as intervention needs for protecting livelihoods in the study area. The results of the study will be helpful in planning adaptation options for future for the study area as well as effectively allocate resources/investments to protect population and livelihoods from possible climate change induced hazards.

\section{Keywords}

Haor, Climate Change, Vulnerability Mapping, Risk Assessment, Participatory Methods, GIS

\section{Introduction}

The Haor region of Bangladesh is a distinct landscape with unique hydro-ecological features situated in between the natural levees of the rivers and highlands. It is a combination of different wetlands such as river, canal, beel etc. which have increased the diversity of this area to a large extent. It includes large areas of seasonally flooded cultivated plains and beels, sporting rich ecosystem that naturally prevails and provides ecological safety net to all lives. Almost all the Haors of Bangladesh are situated in the north-eastern part of the country covering an area of $19,998 \mathrm{sq} \cdot \mathrm{km}$, which is about $15 \%$ of the country [1]. It is a source of one of the most valuable, rich and unique types of biodiversity in the world. It also provides livelihood opportunities and the basic support to the approximately 20 million people living in that area and by doing so; it actively supports the sustainable economic condition of the country [1]. Fisheries and agriculture are the two major sectors upon which the people of this area depend for their livelihoods as around $20 \%$ of Boro rice production, $15 \%$ of the total rice production, $14 \%$ of inland fish production and $84 \%$ of capture fisheries production of the country come from this region.

There has been a great change in the climatic pattern across the world [2]. Bangladesh, due to its geographical position and population density is one of the most affected countries facing climate change impacts. It suffers adverse impact from frequent extreme weather events due to anthropogenic climate change [3] [4] [5] [6]. Because of the geographical setting of the Haor region, the consequences of climate change have made this area highly vulnerable to natural disasters. Most of the Haor areas remain under water for about $6-7$ months of a year and a substantial portion is perennial wetland [1]. Flash flood is the main disaster in the Haor area, which engulfs the primary production sector (e.g., agriculture) and thus threatens the lives and livelihoods of the people. Excess rainfall in the upstream hilly areas and subsequent runoff coupled with sedimentation in the rivers, improper drainage, unplanned road and water man- 
agement infrastructure and the effect of climate variability can be viewed as the main reasons for the devastation caused by flash floods [1] [7] [8]. In recent years, frequency of thunderstorms has been increased in Haor area. Ahmed (2001) and BCAS (2012) indicate that climate change will affect the Haor region and will disproportionately affect the subsistent farmers and women. Maintenance of livelihoods for the affected groups under climate change will be a major challenge [9] [10].

In this context, the present study illustrates community based climate change risk assessment carried out in the Haor region of Bangladesh. The community level knowledge on hazards and vulnerability has been collected and blended with scientific methods on multi criteria analysis and finally GIS based spatial analysis has been done to prepare multi hazard risk hotspot maps. The purpose of the research is to provide the govt officials with appropriate information scopes to undertake development project to secure livelihoods of the farmers and fishermen.

\section{Study Area}

The Haor region of Bangladesh is a saucer shaped shallow depression which is an internationally recognized important wetland ecosystem. Around $44 \%$ of the total Haor area is covered within the districts of Sylhet, Sunamganj, Moulvibazar, Habiganj, Netrokona, Brahmanbaria and Kishoreganj. The Haor Basin is surrounded by the mountain ranges of India, with Meghalaya to the north, Tripura and Mizoram to the south, and Manipur and Assam to the east. It is a mosaic of wetland habitats, which includes rivers, streams, irrigation canals, large areas of seasonally flooded cultivated plains and hundreds of Haors and beels. The study area includes 28 Upazillas of the 5 Haor districts i.e. Sunamganj, Habiganj, Netrokona, Brahmanbaria and Kishoreganj inside the Haor areas. It includes about 166 Haors and some 6300 beels of varying size, out of which about 3500 are permanent and 2800 are seasonal [1]. Figure 1 presents the geographic location of the study area along with the topographic condition in the area. It is clear from the elevation data that most of the area in the study area is below 2 meters from mean sea level.

\section{Materials and Methods}

This section elaborates the data collection procedure, approach and methodology followed to conduct the research using blended scientific and participatory tools:

\subsection{Data Collection}

The participatory methods of focus group discussions (FGDs) [11] and Key Informant Interviews (KIIs) [12] have been followed in data collection for community-based climate change risk assessment. Location of KII and FGDs are shown in Figure 2. The preliminary vulnerable unions have been identified 


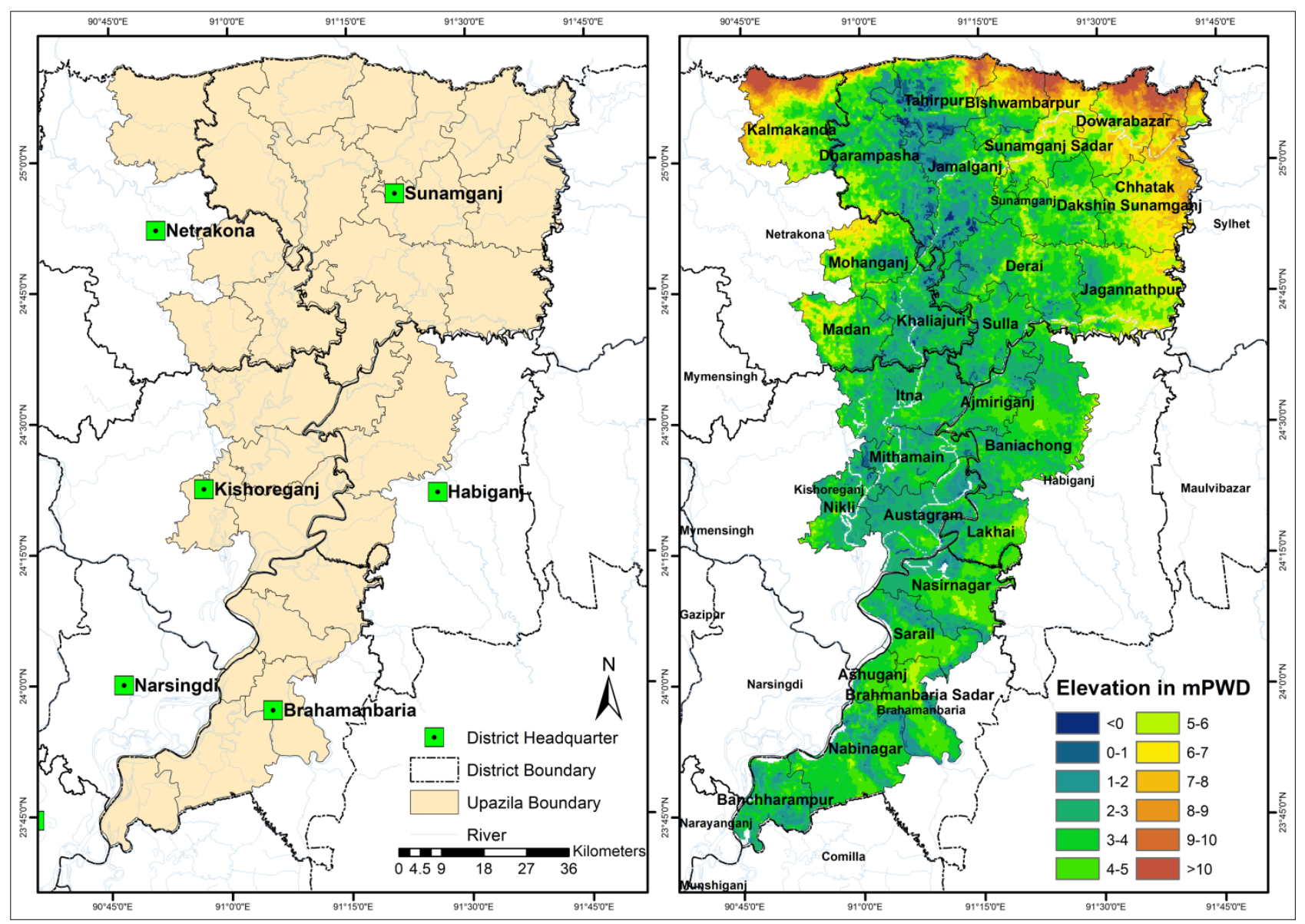

Figure 1. Geographic location of the study area (left) topography of the study area (right).

through preliminary field visit and conducting KIIs with relevant local level government officials from agriculture department, fisheries department and LGED. A total of 56 FGDs have been conducted in the most vulnerable parts of the study area. Local level stakeholders from community specifically farmers, fishermen, women, local influential people, labourers, marginal people etc. participated in the FGDs.

The sessions were pre-arranged following standard participatory norms of FGDs. The checklists for the KII and FGDs include the following points:

- Major Risks/Hazard (e.g., Drought/Hail Strom/Flash Flood etc.) in the Upazilla

- Most vulnerable area of this Upazilla in terms of risk and hazard

- Local perceptions on risks (i.e. drought/hail storm/flash flood)

- Causes, Frequency, intensity and specific month/season/time for each risks

- Identify possible hazards due of climate change in the area

- Scoring/Ranking of the hazards for the area

- Identify vulnerable groups (e.g., woman, children, elderly people, landless farmers, marginal/small/medium farmers, fishermen, day labourer etc.)

- Possibility of certain climate change induced hazard (likelihood) in past and future

- Hazard impacts and their possible consequences 


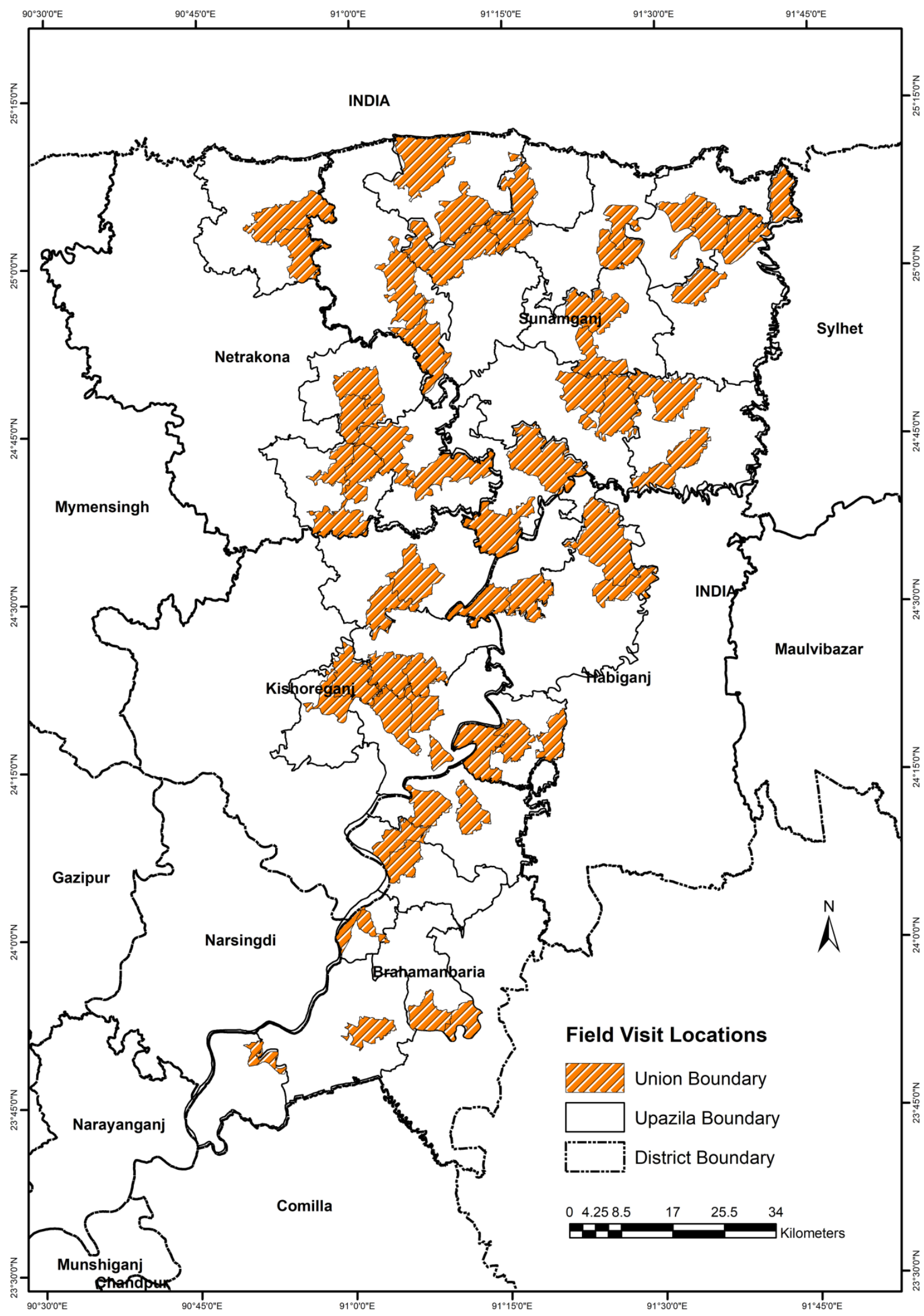

Figure 2. Location of FGDs and KIIs. 


\subsection{Methodology}

Vulnerability and risk assessment encompass various approaches and techniques ranging from indicator-based global or national assessments to qualitative participatory approaches of local level vulnerability and risk assessment [13] [14]. In this study, qualitative risk assessment has been performed focusing particularly in agriculture and fisheries sectors, using both participatory and scientific tools. The overall risk assessment process has been illustrated in Figure 3.

\subsubsection{Data Collection by FGDs}

During FGDs of risk assessment, community perceptions have been counted on identification of vulnerable group of people, occurrences of hazards, probability of occurrences of hazards and extent of potential consequences in the study area due to climate change induced hazards. Simple scoring techniques (Table 1) [15] have been used to gather information on the perceptions of hazard occurrence which has been used for further analysis of climate change risk assessment. Similar approach has been used for gathering perceptions on potential consequences of hazards.

In addition, information on likelihood or probability of occurrence of identified climate change induced hazards has also been gathered from FGDs along with most vulnerable groups. Later, likelihood of occurrence of hazards has been classified following the scale presented in Table 2.

\subsubsection{Risk Calculation}

Risk score has been calculated following the IPCC (2012) defined formula as

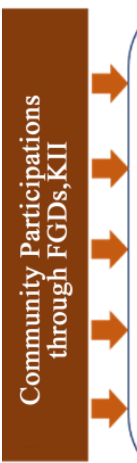

Hazard Assessment

- Occurence

- Vulnerability

Assessment of Likelihood

Consequence Assessment

Weighting for Multi Hazard Risk Mapping
Geo-Spatial Analysis using ArcGIS

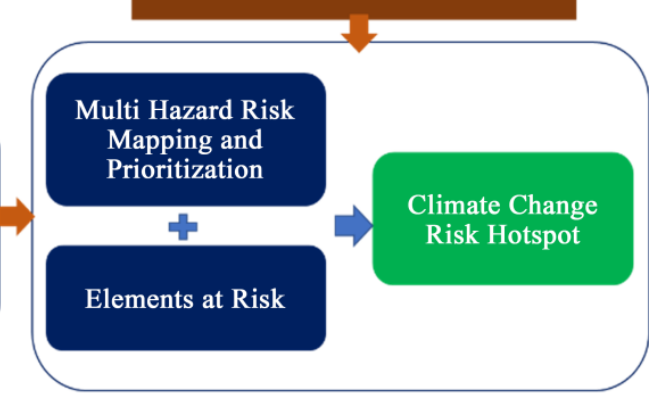

Figure 3. Conceptual framework of the community based climate change risk assessment.

Table 1. Scoring for occurrence of hazards and consequence analysis.

\begin{tabular}{cc}
\hline Level of Impact/Effect & Score \\
\hline No Impact/Effect & 0 \\
Low Impact/Effect & 1 \\
Medium Impact/Effect & 2 \\
High Impact/Effect & 3 \\
\hline
\end{tabular}


Table 2. Scoring for probability of occurrences of hazards.

\begin{tabular}{ccc}
\hline Hazard Occurrence Period in Year & Frequency & Likelihood Score \\
\hline 1 & Very Frequent & 4 \\
2 & Frequent & 3 \\
3 & Moderately Frequent & 2 \\
5 & Less Frequent & 1 \\
10 &
\end{tabular}

Table 3. Classification of normalization score.

\begin{tabular}{cc}
\hline Level of Risk & Range of Normalized Score \\
\hline Low & $\leq 0.4$ \\
Medium & $0.41-0.7$ \\
High & $>0.7$ \\
\hline
\end{tabular}

shown in Equation (1) [14].

$$
\text { Risk }=P * E
$$

where, $P=$ Probability of occurrences of hazards or Likelihoods, $E=$ Extent of consequences due to climate change induced hazards. Scores for likelihood (occurrence) and consequence have been computed based on scoring. In this way, risk score has been found for each of the 28 Upazillas against each of the identified hazards. Normalization of score has been performed to convert the scores to a standard range of 0 to 1 (Equation (2)) [15]. The normalized scores have been classified to set the level of risk following Table 3.

Normalization formula:

Normalized Score $=1-[($ Maximum - Respective Score $) /($ Maximum - Manimum $)]$

\subsubsection{Multi-Hazard Risk Calculation and Prioritization}

Multi-hazard risk score has been calculated by adding the normalized scores of all individual hazards for each Upazillas of the study area. Afterwards, risk level classification has been done using Table 3 to present the level of Multi-hazard risk. Based on this multi hazard risk, priority ranking for 28 Upazillas has been calculated.

\subsubsection{Geo-Spatial Analysis for Risk Hotspot Mapping}

Apart from the priority of the Upazillas in terms of climate change risk particularly focusing on the Agriculture and Fisheries sectors, risk hotspots have been identified in the study area. This hotspot mapping has been done utilising the multi-hazard risk and GIS data layers for the study area and employing spatial analysis techniques. To perform the hotspot mapping, several important elements of risk have been identified, which are directly or indirectly linked with life and properties of the community, if climate change induced hazards occur. These elements have been selected based on literature review and community perception. They are: 
- Settlement

- Health Facilities (Community Clinic, Hospital, Family Welfare Centre)

- Educational Institutes (Primary School, High School, College, Madrasah, University)

- Growth Centre

- Godown

- Ghats

- Rural Market

- Other Key Infrastructures (Mosque, Post Office, Police Stations etc.)

- Embankment of BWDB

- Beels

- Fish Sanctuaries

- LGED Roads

- RHD Roads

- Rail Network

The overlaying has been performed using spatial analyst extension of ArcGIS. Individual data layers were converted to raster layer using either point density or line density tool depending on data type. These data layers and multi hazard risk data have been overlaid using Equation (3)

$$
\text { Total Score }=\sum W_{i} \times S_{i}
$$

where, $W=$ weightage of $1,2,3 \ldots n$ elements at risk and $S=$ Score of the 1,2 , $3 \ldots n$ raster layers.

Here, equal weight has been considered for spatially overlaying, as all of the considered elements at risk are equally important in the study area in context of Agriculture and Fisheries sectors.

Based on the risk hotspot map, a number of unions have been identified where at least thirty percent of its area falls under moderate to severe risk level. This information could be useful for implementing agencies to prioritize development projects.

\section{Results and Discussions}

The following sections describe the outcome of this research for the study area:

\subsection{Important Hazards and Their Consequences}

Based on the FGD findings, temperature rise, erratic rainfall, drought, early flash floods, thunderstorm, Afal or wave action, hailstorm, erosion and siltation and cold snaps are major climate change induced hazards which community people in Haor areas face very frequently. Figure 4 presents the overall scores for each hazard in the Upazillas of the study area.

Among the disasters mentioned above, flash flood, thunderstorm and hailstorm are the main concerns for the Haor region. The FGD participants specified that, every year at least one of these disasters occurs and destroys their crops fully or partially. Figure 4 also shows that, most of the participants of northern 
Upazillas have given more emphasis on early flash flood as the most frequent event while in the southern Upazillas early flash flood got less emphasis.

Potential consequences of climate change induced hazards have been perceived

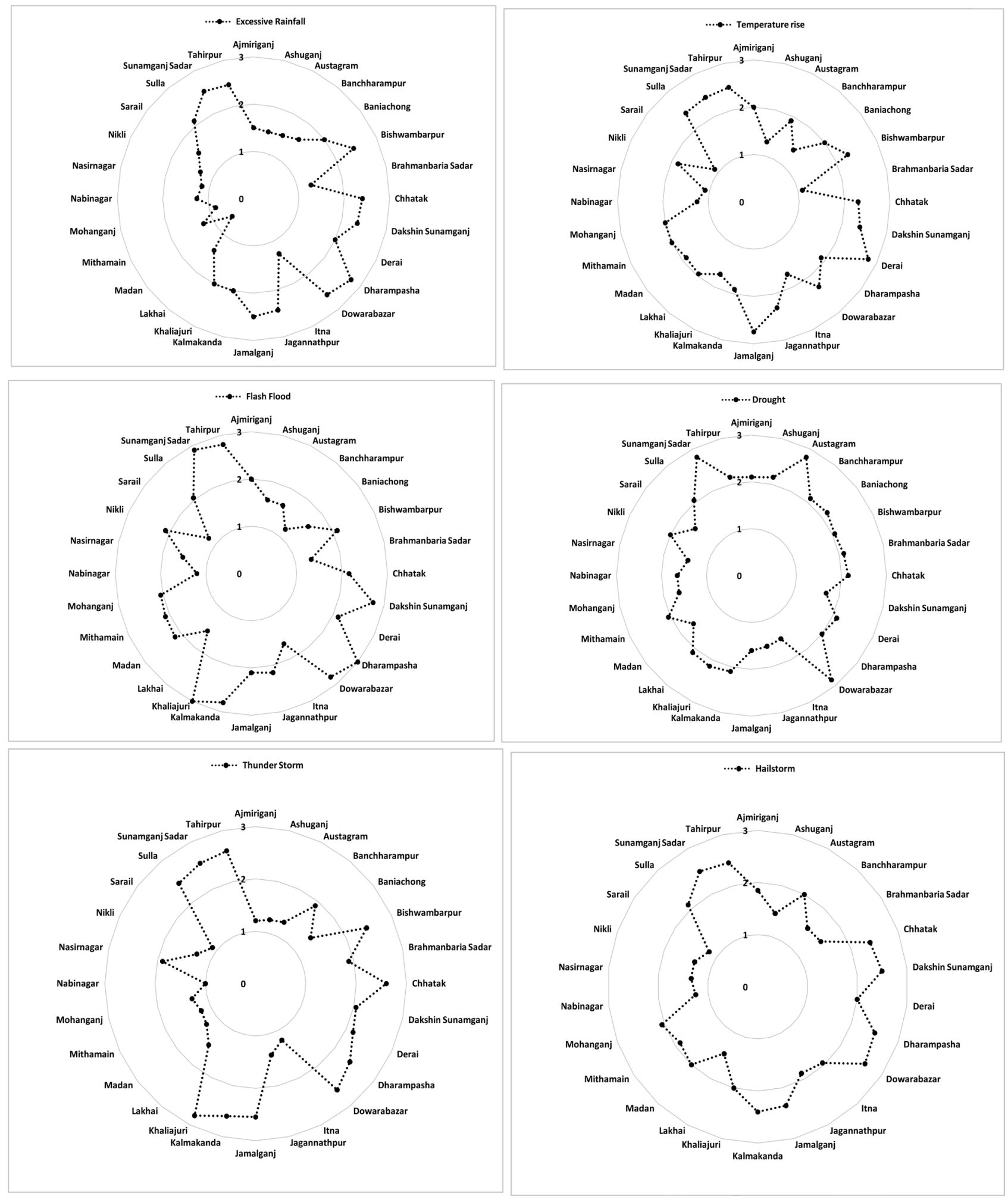




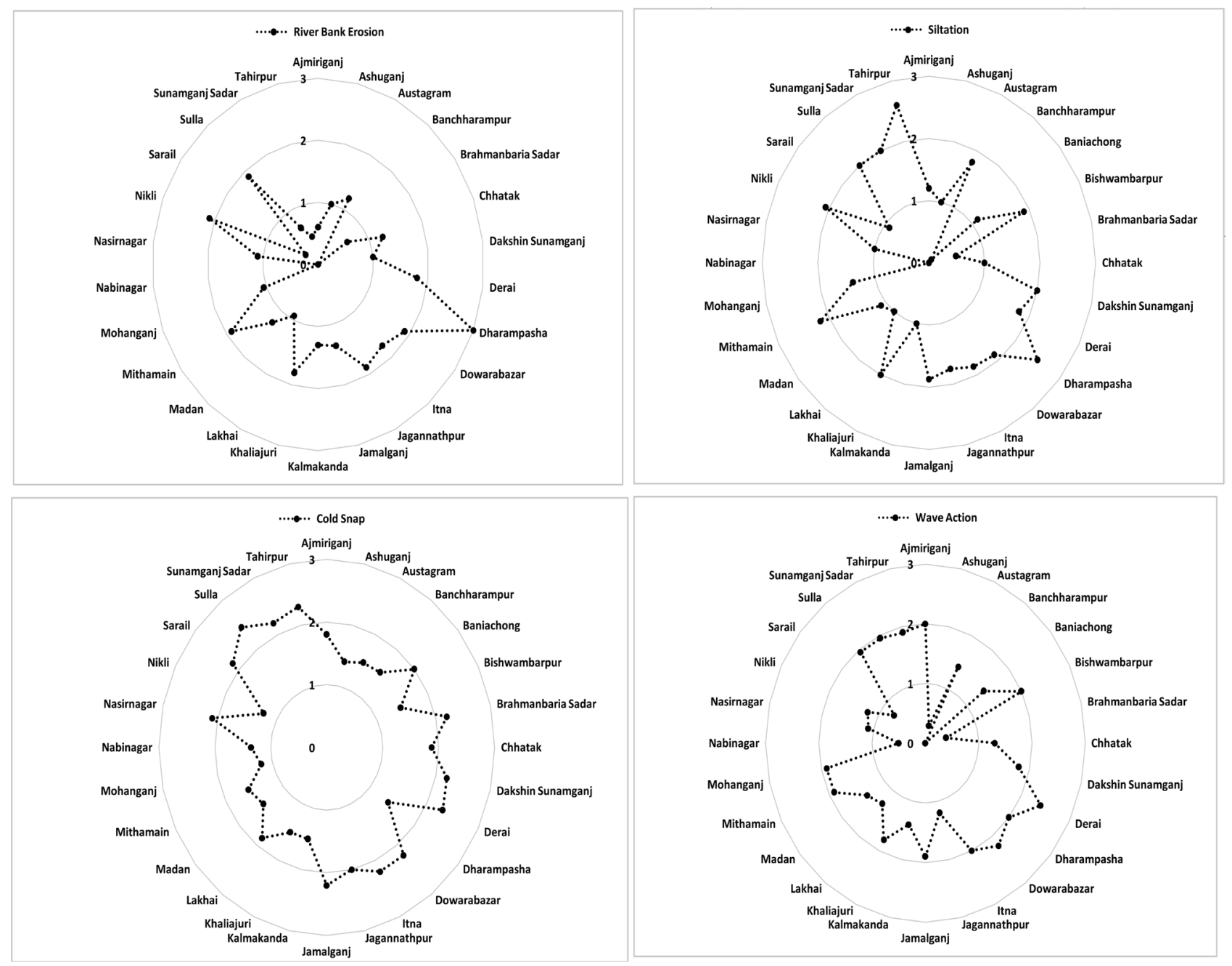

Figure 4. Score (between 0 to 3 ) given by the community on hazard occurrences.

through the FGDs. According to the assessment, most hazardous consequences would be the loss of crops as frequency of early flash floods is increasing and due to damage of crops before harvesting. Although, they did not anticipate massive crop land loss due to those hazards. Loss of households is the second most considered negative consequence which would occur in the study area. There are chances of loss of fish production too but in limited manner according to community perceptions. Most interestingly, community people did not express major concerns over potential loss of income, which indicates that they are used to with the alternative livelihoods, if their main occupations were hampered. Apart from these, anticipations have been made on deterioration of drinking water quality, health issues and hampered education almost uniformly among all the Upazilla, but not severely as crop production loss. Following Figure 5 illustrates consequence scoring by the community people in the study area.

\subsection{Likelihood Assessment}

The FGD participants assessed the likelihood or probability of occurrences of 

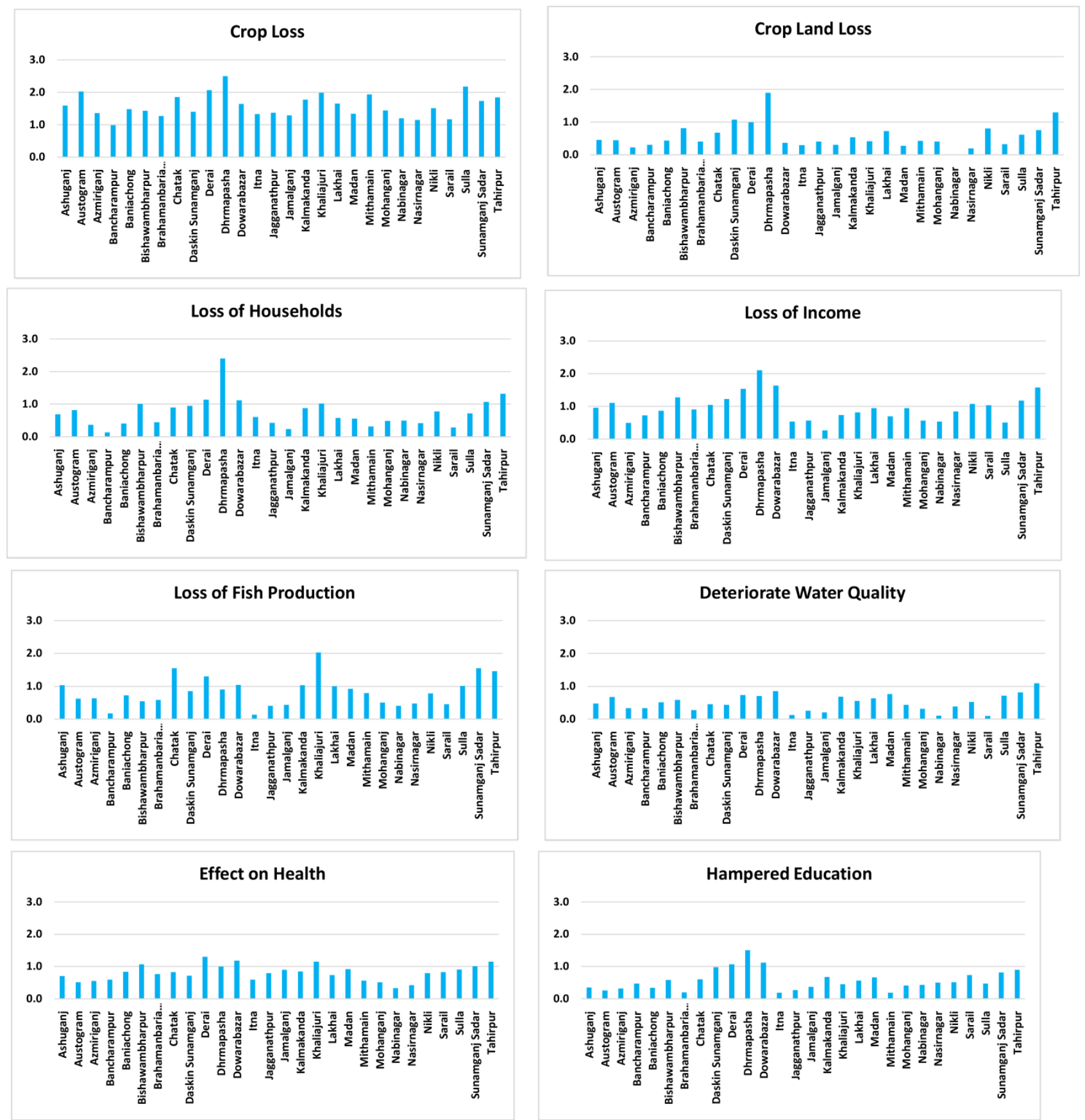

Figure 5. Score given by the community on potential consequences of climate change induced hazards (Y axis indicates unitless score between 0 to 3 ).

different climate change induced hazards (Figure 6). Most of the respondents expressed that temperature rise is very frequent phenomena now and would be as usual in future, whereas excessive rainfall will occur once in 2 to 3 years. The frequency of the occurrence of early flash floods would be as excessive rainfall i.e. once in 2 to 3 years, as early flash floods is mostly triggered by excessive rainfall. Respondents from Nabinagar of Brahmanbaria District only opined that there would be very less probability to occur early flash floods in that area. 

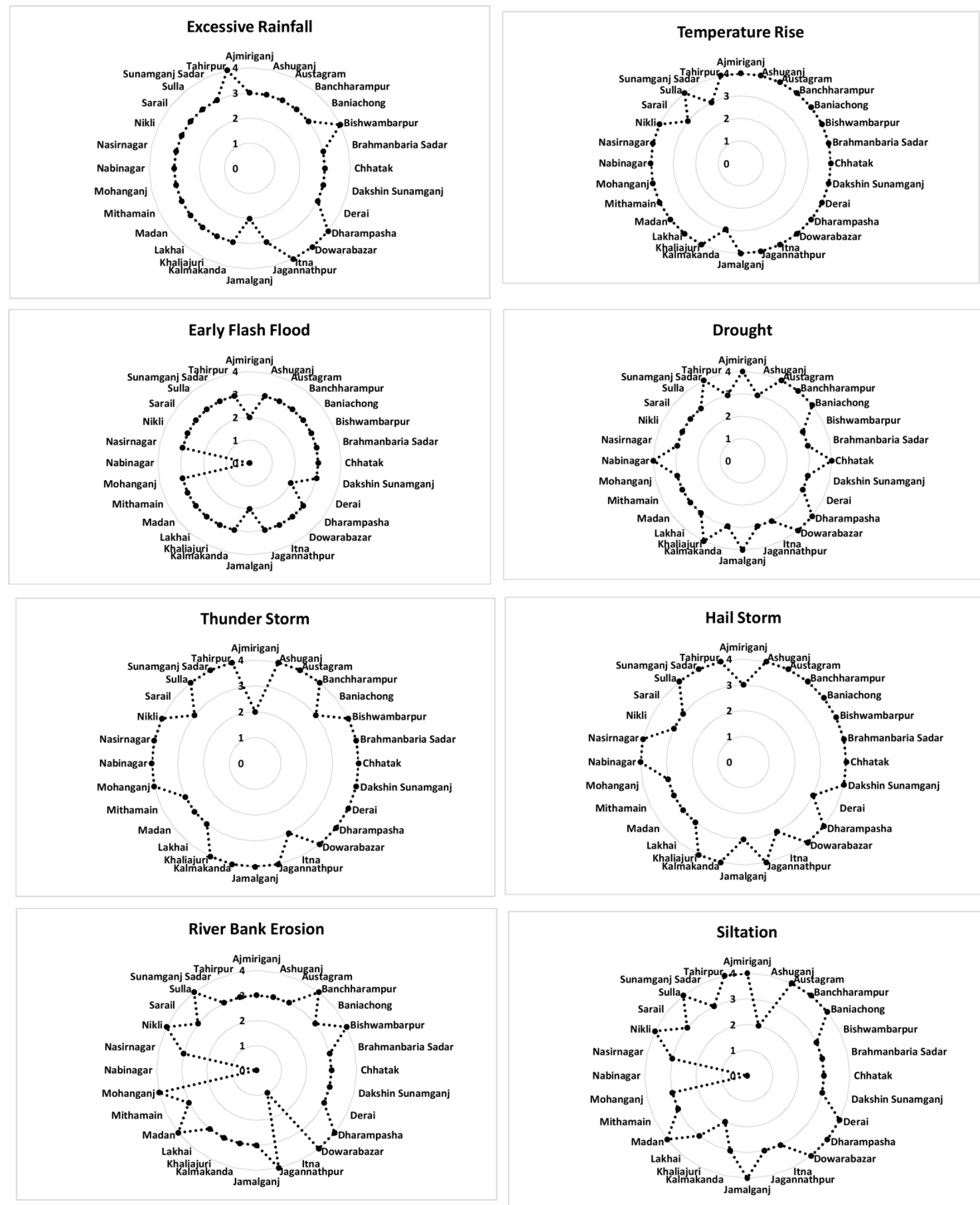

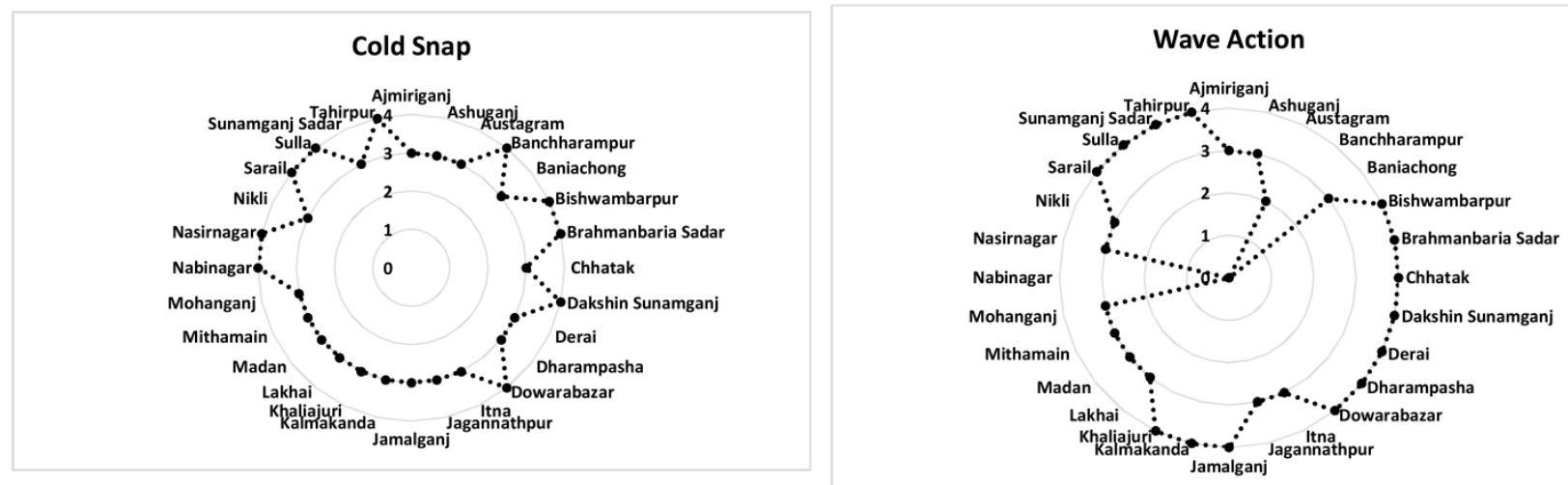

Figure 6. Community perceptions (score given between 1 to 4 ) on likelihood of occurrences of climate change induced hazards.

Thunderstorm and hailstorm are occurring damage very frequently i.e. almost every year according to the perceptions of community people, which will prevail in future too. Mixed feedback has been found regarding likelihood assessment of drought. Either once in each year or within 2 to 3 years, drought may occur in the area. Erosion and siltation problem would be severe once in $2-3$ years according to their perceptions. People of Sunamganj and Netrokona face severe wave action problem almost in every year than other parts of the study area. In other parts, frequency of occurrence has been perceived as once in 2 to 3 years. Likelihood of occurrence of cold snaps is found also as of highly frequent, not very high.

\subsection{Risk Assessment for Different Hazards}

The risk due to individual hazards for each of the Upazillas has been assessed following the methodology described. Figure 7 illustrates the spatial variation of climate change risk for individual hazards. The results show that, Kalmakanda, Sunamganj Sadar, Dakshin Sunamganj, Dhamrapasha, Khaliajuri, Dowarabazar and Tahirpur Upazillas are in high climate change risk due to early flash floods, whereas, Bishwambharpur, Jamalganj, Derai Upazillas are under medium risk level despite being located in the deeply flooded area. But the normalized scores for these Upazillas are quite close to lower threshold of the high risk category i.e. 0.7. Therefore, the risk map shows the variation of risk in a relative scale, which may vary on the basis of the overall understanding of the local context. Sometimes, the risk map due to individual hazard shows sudden or irregular changes in the risk level, which may be due to the variation of community perceptions and lack of homogeneity in the knowledge level of groups of community people.

\subsection{Multi-Hazard Risk Calculation and Prioritization}

The multi-hazard risk map has been prepared taking weighted sum of the normalized score of each hazard for each Upazilla. The weight for multi-hazards has been derived from the FGDs outcomes (Figure 8). According to the community preferences, early flash floods and drought both got highest $12 \%$ weightage, $11 \%$ weightage for temperature rise, hail storm and thunder storm while river bank erosion and wave action was given less emphasis ( $8 \%$ weightage). 

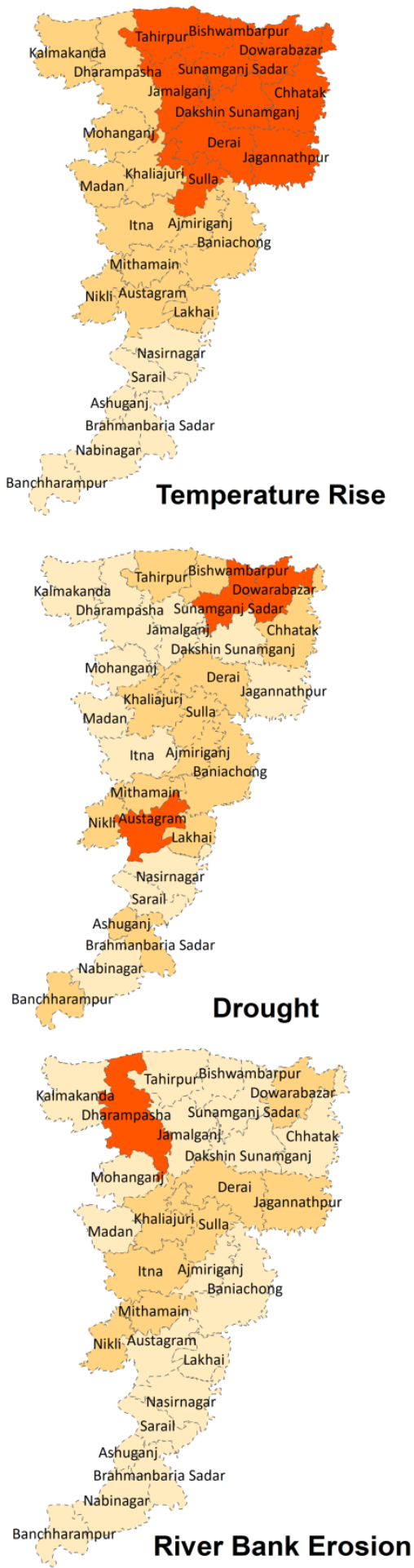

Among all the identified climate change induced hazards. Total weightage has been counted in a scale of 100. Based on this information, the multi-hazard weighted sum of normalized scores has been calculated for each of the $28 \mathrm{Upa}$ zillas considering same combination of weights for each Upazilla.

Finally, multi-hazard climate change risk map has been produced from the calculated total normalized score. Figure 9 shows the multi-hazard climate change
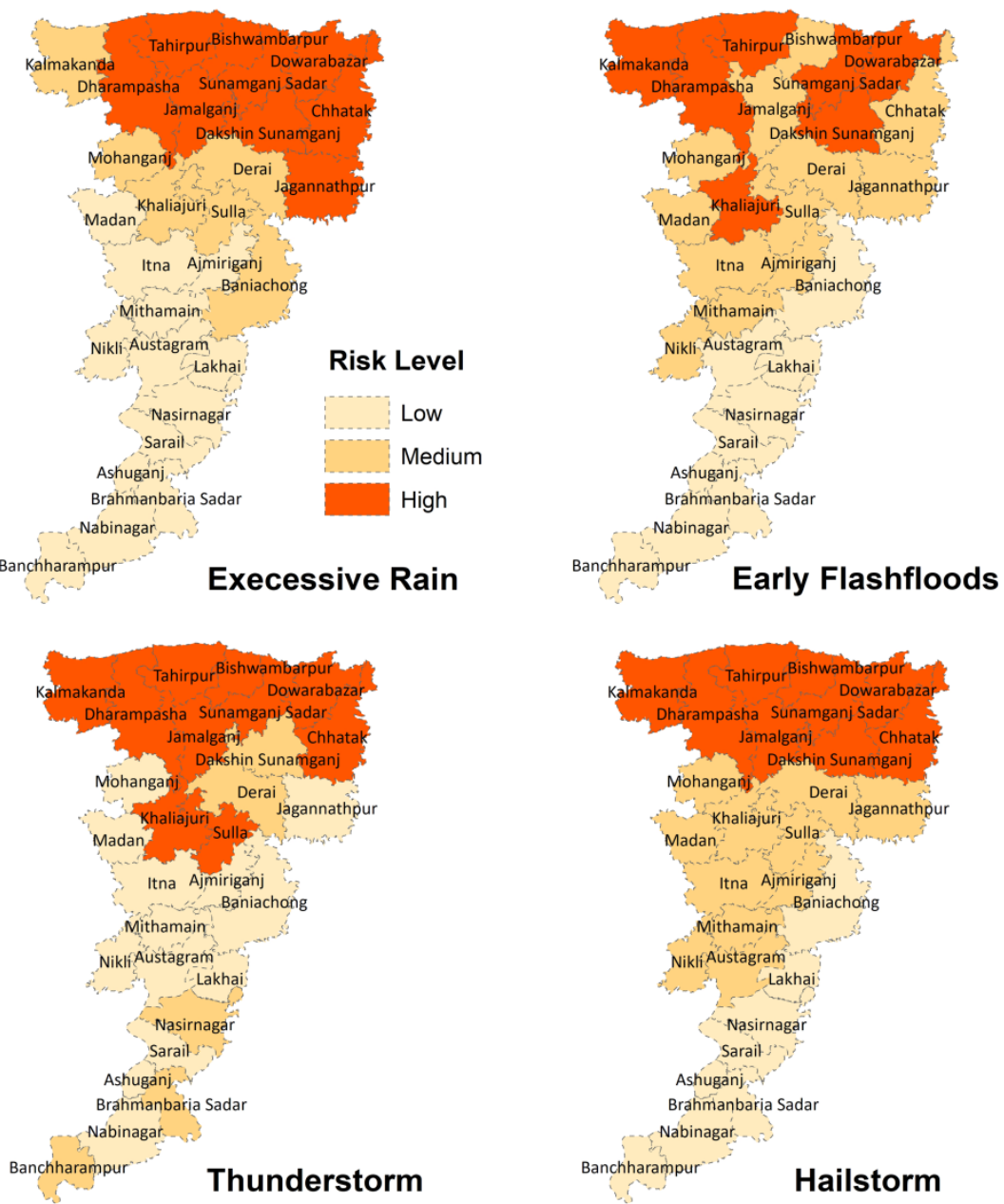
Banchharampur

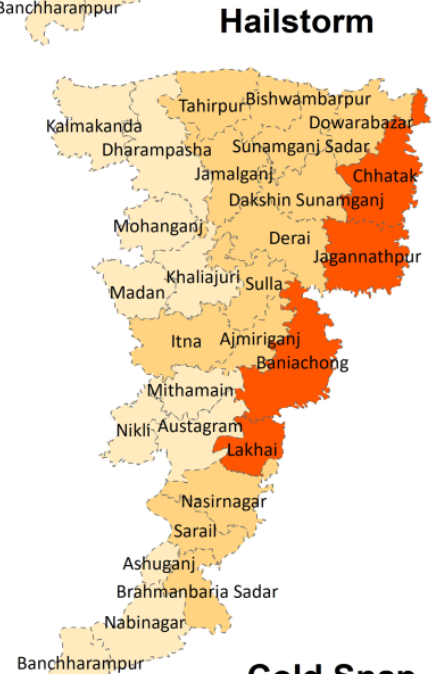




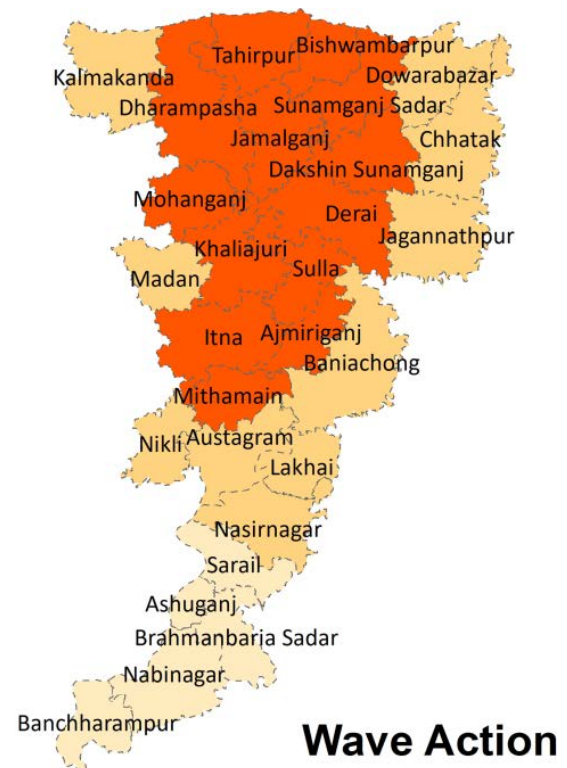

Figure 7. Climate change risk map for different hazards.

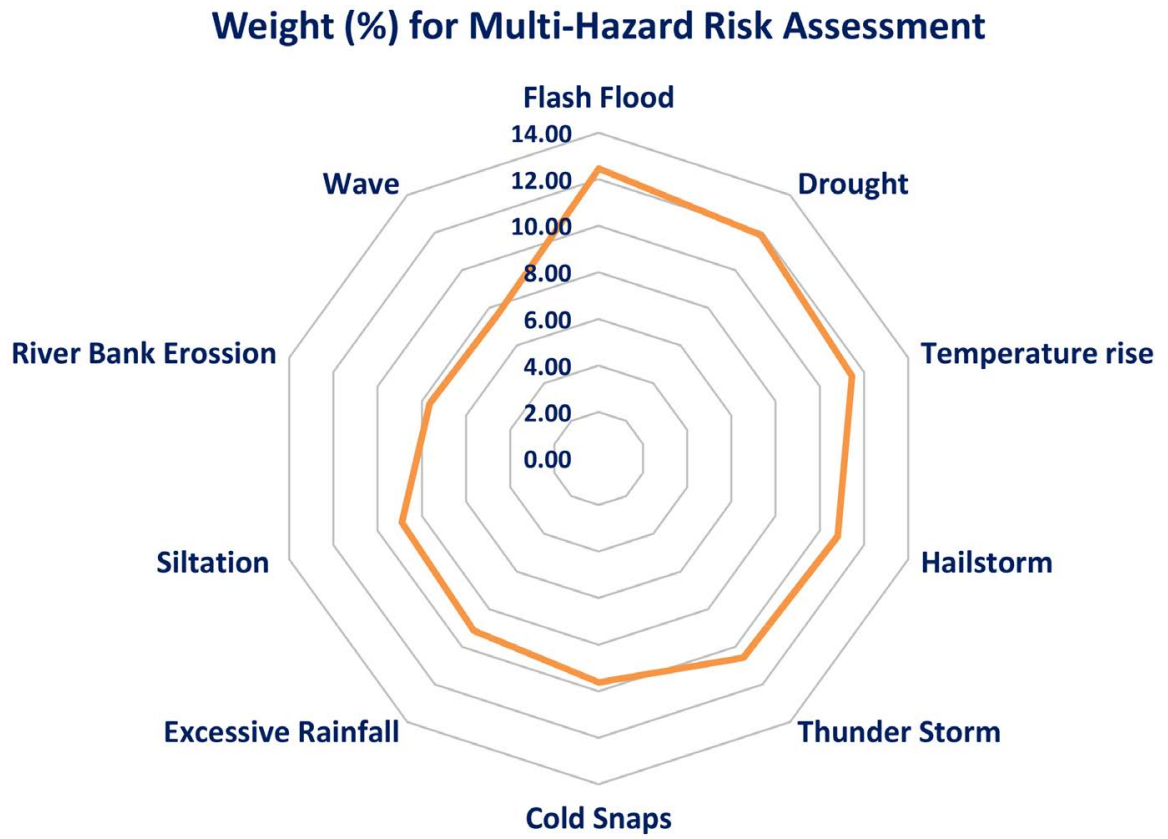

Figure 8. Weight derived from community perceptions for multi-hazards.

risk map with priority rank of different Upazillas. The developed multi- hazard risk map has been found very consistent with other study results (e.g., [1] [16]).

According to the multi-hazard risk map, 12 Upazillas have been found to be under high risk, 11 Upazillas under medium risk and 5 Upazillas under low risk. Mostly, north-eastern Upazillas are in high risk category. A priority rank of the Upazillas has been prepared using the calculated normalized score. Among all Upazillas, those of Sunamganj District and one Upazilla from Netrokona District are considered as high priority in terms of multi-hazard climate change risk in the study area. 


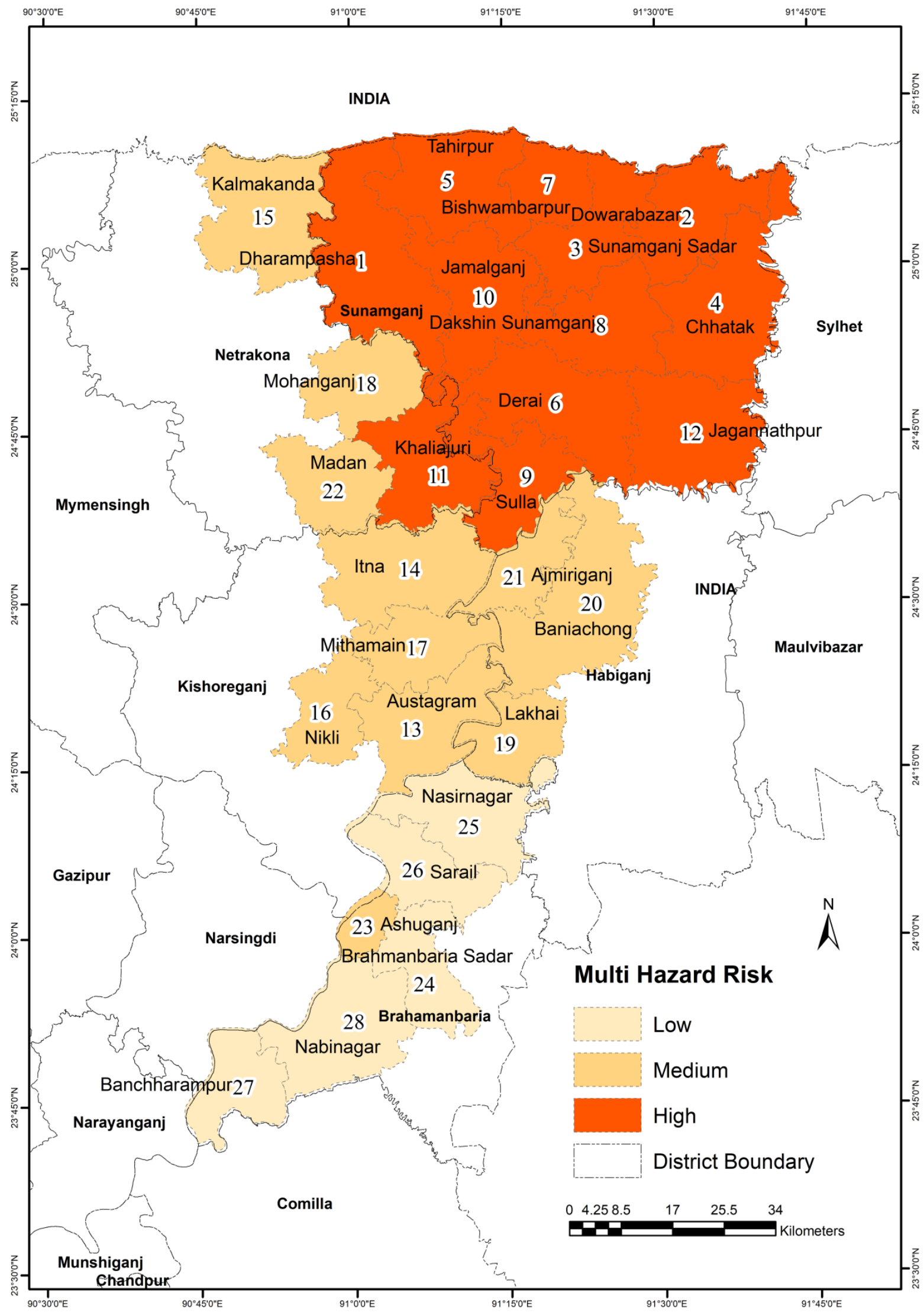

Figure 9. Climate change risk map due to multi-hazards with risk rank of Upazilas. 


\subsection{Geo-Spatial Analysis for Risk Hotspot Mapping}

For the geo-spatial analysis, identifying the elements at risk is a key component. The study team tried to identify the most important elements which may face risk due to climate change induced hazards using the community perceptions i.e. socio-economic context analysis from this study as well as from relevant literatures. As, socio-economic resources and infrastructures will be worst affected due to the climate change induced hazards, which are also directly linked with life and livelihood of the community people, most of the elements are identified from these categories. Apart from that, perennial beels and fish sanctuaries have been considered as elements at risk due to the particular focus of this study on agriculture and fisheries sector. The submersible embankments of BWDB or LGED both are very crucial for the study area in connection with crop production as well as for maintaining communication or connectivity with other parts of the country, therefore, roads, embankment and rail networks are also considered as elements at risk.

Density of these elements of risk has been analysed to identify which part of the study area has most densely populated elements at risk. These analyses have facilitated further to identify hotspot risk areas in the study area. Figure 10 illustrates the spatially varied density of elements at risk in the study area along with

(a)

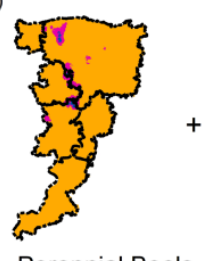

(h)

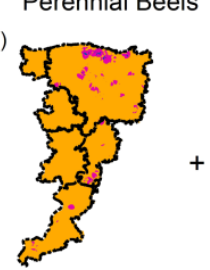

Health Facilities (b)

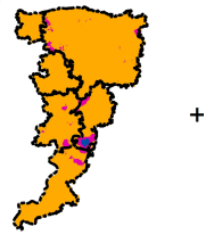

(i)

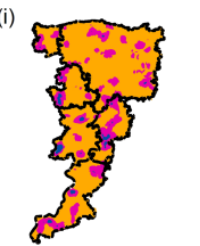

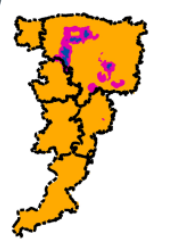

Embankment

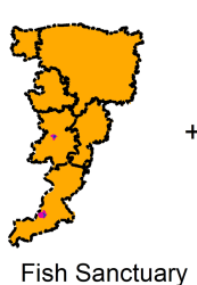

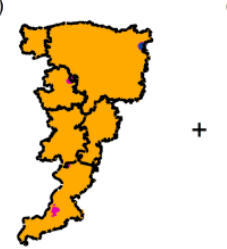

Ghats

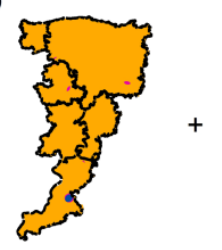

Godown (g)

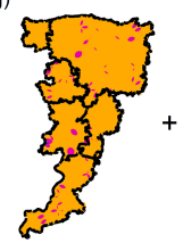

Growth Center

(j)

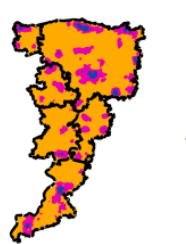

k)
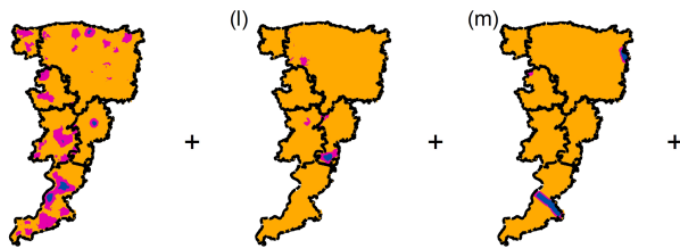

(n)

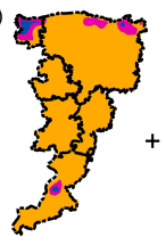

Rail Network

Settlement

(o)

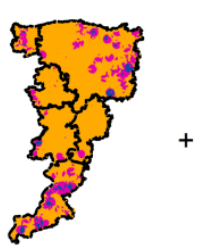

Rural Market (p)

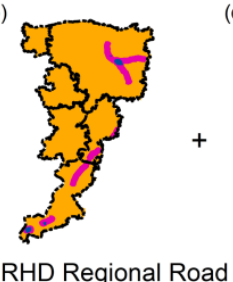

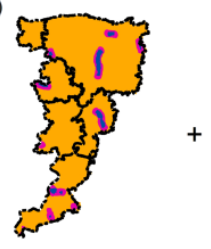

(r)

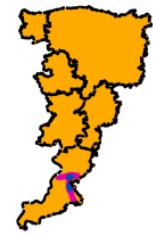

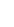

Other Infrastructures

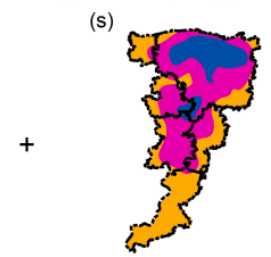

Climate Change Risk

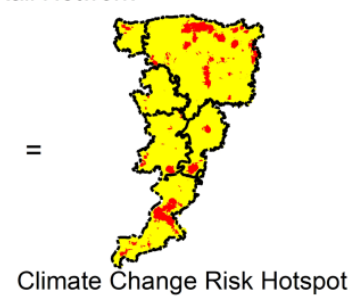

Climate Change Risk Hotspot

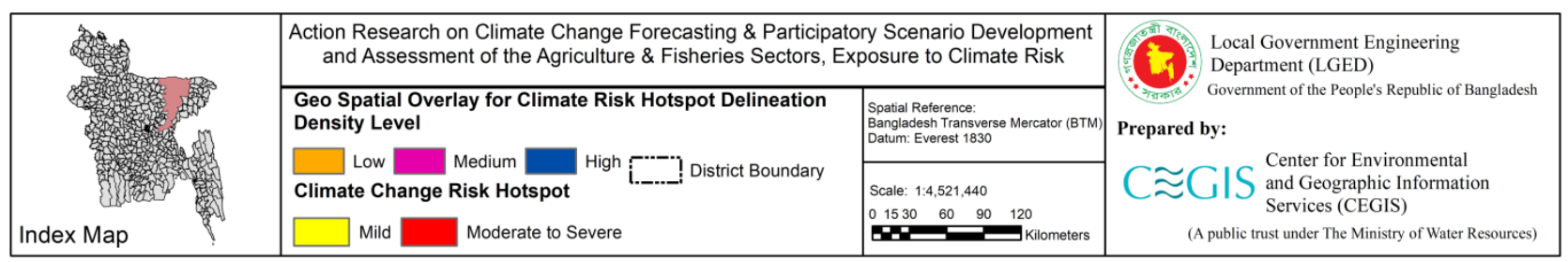

Figure 10. Weighted overlay of elements at risk and multi-hazard climate change risk to identify climate change risk hotspot. 
the weighted overlay process.

After the weighted overlay, a climate change risk hotspot map has been prepared (Figure 11), which specifically depicts the site-specific areas which

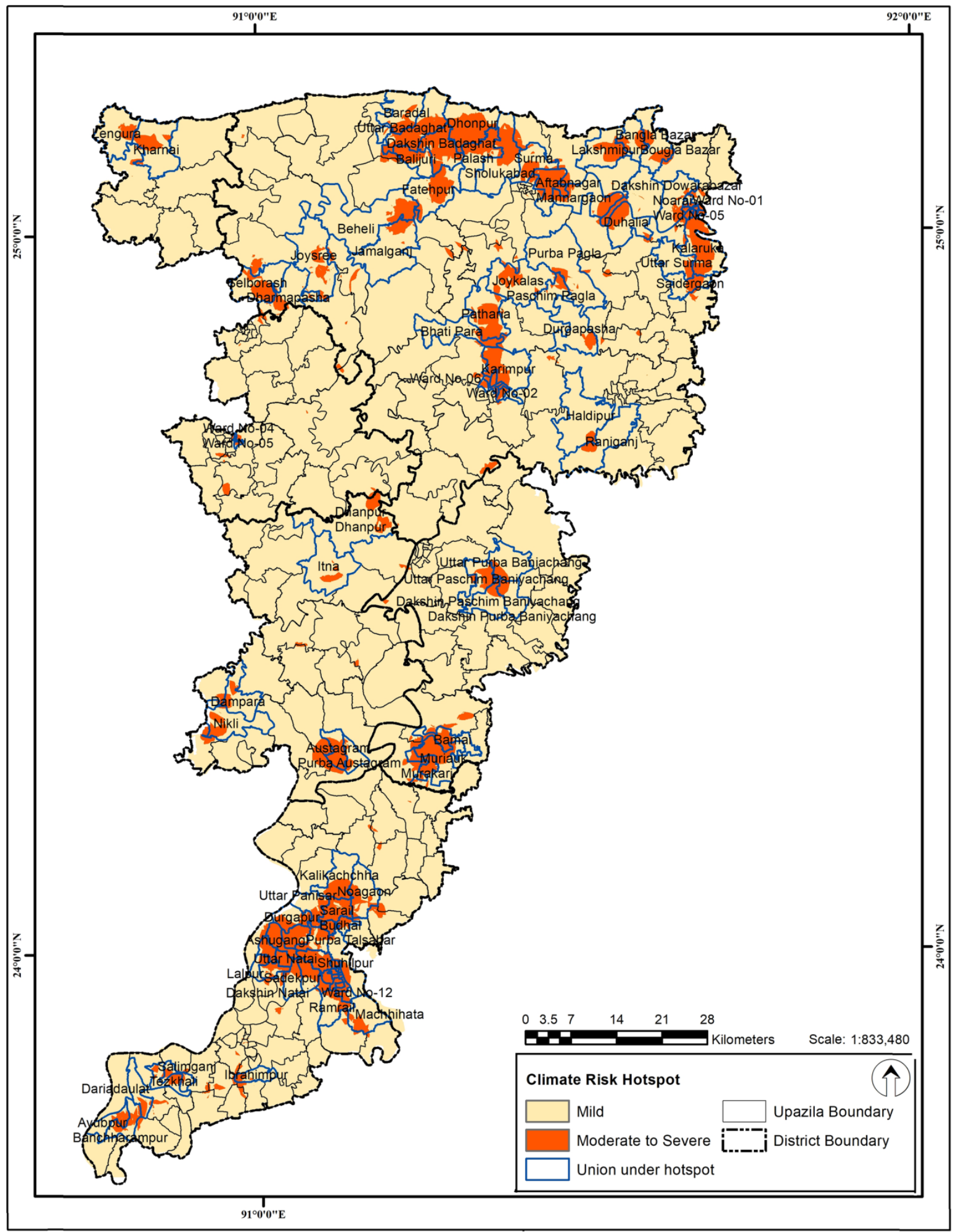

Figure 11. Climate change risk hotspot of the study area. 
should be considered for immediate interventions in terms of potential risk due to climate change induced hazards. Around 100 unions (Table 4) have been identified as climate change risk hotspot area. Some unions in the southern part of the study area are found as risk hotspot, despite being located in low climate change risk level as the elements at risk are very densely located in those areas.

\section{Conclusion}

This study investigates the climate change risk due to multiple hazards in the

Haor area of Bangladesh. The participatory approach combines geo-spatial methods

Table 4. Identified climate change risk hotspot.

\begin{tabular}{|c|c|c|}
\hline District & Upazilla & Union \\
\hline \multirow[t]{5}{*}{ Brahamanbaria } & Banchharampur & Ayubpur, Dariadaulat, Tezkhali, Banchharampur \\
\hline & Brahmanbaria Sadar & $\begin{array}{l}\text { Ward No-01, Ward No- } 02 \text {, Ward No-03, Ward No- } 05 \text {, Ward No-06, Ward No- } 07 \text {, Ward No-08, Ward } \\
\text { No-09, Ward No-11, Ward No-12, Dakshin Natai, Shuhilpur, Machhihata, Purba Talsahar, Ramrail, } \\
\text { Sadekpur, Uttar Natai, Budhal }\end{array}$ \\
\hline & Ashuganj & Araisidha, Ashugang, Durgapu, Lalpur, Paschim Talsahar, Sharifpur, Tarua \\
\hline & Nabinagar & Ibrahimpur, Salimganj \\
\hline & Sarail & Kalikachchha, Noagaon, Sarail, Uttar Panisar \\
\hline \multirow[t]{2}{*}{ Habiganj } & Baniachong & $\begin{array}{l}\text { Uttar Purba Baniachang, Uttar Paschim Baniyachang, Dakshin Purba Baniyachang, Dakshin Paschim } \\
\text { Baniyachang }\end{array}$ \\
\hline & Lakhai & Bamai, Murakari, Muriauk \\
\hline \multirow[t]{3}{*}{ Kishoreganj } & Austagram & Austagram, Purba Austagram \\
\hline & Itna & Dhanpur, Itna \\
\hline & Nikli & Dampara, Nikli \\
\hline \multirow[t]{2}{*}{ Netrokona } & Kalmakanda & Kharnai, Lengura \\
\hline & Madan & Ward No-04, Ward No-05 \\
\hline \multirow[t]{12}{*}{ Sunamganj } & Bishwambarpur & Dakshin Badaghat, Dhonpur, Fatehpur, Palash, Sholukabad \\
\hline & Chhatak & $\begin{array}{l}\text { Ward No-01, Ward No-03, Ward No- } 05 \text {, Ward No-06, Ward No-07, Ward No-08, Ward No-09, } \\
\text { Kalaruka, Noarai, Saidergaon, Uttar Surma }\end{array}$ \\
\hline & Dakshin Sunamganj & Patharia \\
\hline & Derai & Ward No-01, Ward No-02, Ward No-06, Ward No-07, Ward No-08, Ward No-09, Bhati Para, Karimpur \\
\hline & Dharampasha & Joysree, Selborash \\
\hline & Dowarabazar & Bougla Bazar, Dakshin Dowarabazar, Duhalia, Lakshmipur, Mannargaon, Bangla Bazar \\
\hline & Jamalganj & Beheli, Jamalganj \\
\hline & Sunamganj Sadar & Aftabnagar, Surma \\
\hline & Tahirpur & Balijuri, Uttar Badaghat, Baradal \\
\hline & Dakshin Sunamganj & Durgapasha, Joykalas, Paschim Pagla, Purba Pagla \\
\hline & Dharampasha & Dharmapasha \\
\hline & Jagannathpur & Haldipur, Raniganj \\
\hline
\end{tabular}


to generate risk hotspot map which will facilitate local government engineers, local agriculture and fisheries officials, related stakeholders and decision makers to make choice on the intervention as well as intervention needs for protecting livelihoods in the study area. The results of the study will be helpful in planning adaptation options for future for the study area as well as effectively allocate resources/investments in different interventions to protect the population and their livelihood from possible climate change induced hazards.

\section{Acknowledgements}

This publication is based on the outcome of the research under the Haor Infrastructure and livelihood Improvement Project (HILIP) including Climate Adaptation and Livelihood Protection (CALIP) project of Local Government Engineering Department (LGED), Government of the People's Republic of Bangladesh, which is funded by the International Fund of Agriculture Development (IFAD). Therefore, the authors are grateful to the HILIP-CALIP project and the funding agency IFAD providing the opportunities of this research and financial grants to complete the research respectively. The authors show the gratitude to the inhabitants of Haor areas those who have provided many information and supports.

\section{Conflicts of Interest}

The authors declare no conflicts of interest regarding the publication of this paper.

\section{References}

[1] CEGIS (2012) Master Plan of Haor Area. Bangladesh Haor and Wetland Development Board, Dhaka.

[2] IPCC (2013) Climate Change 2013: The Physical Science Basis. Contribution of Working Group I to the Fifth Assessment Report of the Intergovernmental Panel on Climate Change. Cambridge University Press, Cambridge, New York, 1535.

[3] MoEF (2005) National Adaptation Programme of Action. Ministry of Environment and Forests, Dhaka.

[4] MoEF (2009) Bangladesh Climate Change Strategy and Action Plan. Ministry of Environment and Forests, Dhaka.

[5] Eckstein, D., Künzel, V., Schäfer, L. and Winges, M. (2020) Global Climate Risk Index 2020. Who Suffers Most from Extreme Weather Events? Weather-Related Loss Events in 2018 and 1999 to 2018. Germanwatch.

[6] GED (2018) Bangladesh Delta Plan 2100, Baseline Studies on Disaster and Environment Management (Volume 2), Bangladesh Planning Commission. Ministry of Planning, Dhaka.

[7] Hossain, M.A.R. and Naser, M.N. (2014) Assessment of Agro-Ecological Zone Specific Risks, Vulnerabilities of Disaster and Climate Change and Climate Change Adaptation (CCA) in Fisheries Sector of Bangladesh-Draft Report. Disaster and Climate Risks Management in Fisheries Project. Department of Fisheries/CDMP-II, Dhaka. 
[8] Kartiki, K. (2011) Climate Change and Migration: A Case Study from Rural Bangladesh. Gender Development, 9, 23-38. https://doi.org/10.1080/13552074.2011.554017

[9] Ahmed, A.U. (2001) Adaptability of Bangladesh's Crop Agriculture to Climate Change: Possibilities and Limitations. Asia Pacific Journal of Environmental Development, 7, 71-93.

[10] BCAS (2012) 1st National Conference Community Based Adaptation to Climate Change in Bangladesh 08-09 April 2012, Dhaka.

[11] Morgan, D.L. (1996) Focus Groups. Annual Review of Sociology, 22, 129-152. https://doi.org/10.1146/annurev.soc.22.1.129

[12] USAID (1996) Conducting Key Informant Interviews, Performance Monitoring \& Evaluation TIPS. USAID Center for Development Information and Evaluation, Washington DC.

[13] Brooks, N. (2003) Vulnerability, Risk and Adaptation: A Conceptual Framework. Tyndall Centre Working Paper 38.

[14] IPCC (2012) Managing the Risks of Extreme Events and Disasters to Advance Climate Change Adaptation. A Special Report of Working Groups I and II of the Intergovernmental Panel on Climate Change. Cambridge University Press, Cambridge, and New York.

[15] BMZ (2014) The Vulnerability Sourcebook: Concept and Guidelines for Standardized Vulnerability Assessments. GIZ in Cooperation with ADELPHI and EURAC.

[16] MoEFCC (2018) Nationwide Climate Vulnerability Assessment in Bangladesh. Ministry of Environment and Forests and GIZ, Dhaka. 